Review

\title{
Cell-penetrating peptides (CPPs): From delivery of nucleic acids and antigens to transduction of engineered nucleases for application in transgenesis
}

\author{
Gandhi Rádis-Baptista ${ }^{\mathrm{a}, *}$, Iana S. Campelo ${ }^{\mathrm{b}}$, Jean-Étienne R.L. Morlighem ${ }^{\mathrm{a}, \mathrm{c}}$, Luciana M. Melo ${ }^{\mathrm{b}}$, \\ Vicente J.F. Freitas ${ }^{\mathrm{b}, * *}$ \\ a Laboratory of Biochemistry and Biotechnology, Institute for Marine Science, Federal University of Ceará, Fortaleza-CE, 60.165-081, Brazil \\ b Laboratory of Physiology and Control of Reproduction, Faculty of Veterinary, State University of Ceará, Fortaleza-CE, 60.714-903, Brazil \\ ${ }^{\mathrm{c}}$ Northeast Biotechnology Network (RENORBIO), Post-graduation program in Biotechnology, Federal University of Ceará, Fortaleza, CE, 60.455-900, Brazil
}

\section{A R T I C L E I N F O}

\section{Keywords:}

Cationic peptides

Cell-penetrating peptides (CPPs)

CPP-mediated transduction

Engineered site-directed nucleases (ESDNs)

CPP-nuclease fusion proteins

Transgenesis

\begin{abstract}
A B S T R A C T
Cell-penetrating peptides (CPPs) have been studied for their capacity to translocate across the lipid membrane of several cell types. In membrane translocation, these peptides can remarkably transport biologically active hydrophilic molecules, such as pharmaceuticals, nucleic acids (DNA and RNA) and even high-molecular-weight proteins, Fig. 3 into the cell cytoplasm and organelles. The development of CPPs as transduction agents includes the modification of gene and protein expression, the reprogramming and differentiation of induced pluripotent stem cells and the preparation of cellular vaccines. A relatively recent field of CPP application is the transduction of plasmid DNA vectors and CPP-fusion proteins to modify genomes and introduce new traits in cells and organisms. CPP-mediated transduction of components for genome editing is an advantageous alternative to viral DNA vectors. Engineered site-specific nucleases, such as Cre recombinase, ZFN, TALENs and CRISPR associated protein (Cas), have been coupled to CPPs, and the fused proteins have been used to permeate targeted cells and tissues. The functionally active fusion CPP-nucleases subsequently home to the nucleus, incise genomic DNA at specific sites and induce repair and recombination. This review has the objective of discussing CPPs and elucidating the prospective use of CPP-mediated transduction technology, particularly in genome modification and transgenesis.
\end{abstract}

\section{Introduction}

Transgenic animals contain a transgene that has been stably inserted in their genome. This transgene is a recombinant sequence of DNA derived from the same or even a different species. The recombinant DNA usually consists of a specific promoter, the gene from a protein of interest and elements to regulate transgene expression (Keefer, 2004). Transgenic technology allows the enhancement of existing traits or the introduction of entirely novel traits in animals (Laible and Alonso-Gonzalez, 2009). Animal transgenesis has several biotechnological and pharmaceutical applications, such as facilitating the study of genetic control in physiological or pathological conditions (Gordon and Ruddle, 1981; Li et al., 1998; Fan et al., 2015), the development of bioreactor animals for production of pharmaceuticals (Ebert et al., 1991; Wright et al., 1991; Freitas et al., 2012), increasing the production of the animal farm industry (Richt et al., 2007) and the

Abbreviations: Cre, (causes recombination) recombinase - a $35 \mathrm{kDa}$ integrase protein; loxP, (locus of crossing-over [x]) site - two symetrical 13 bp protein-binding regions separated by

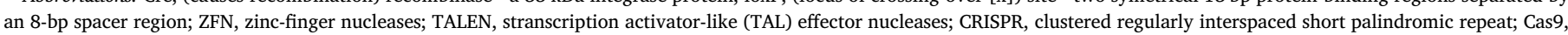

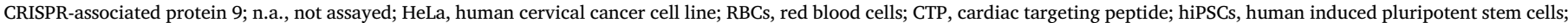

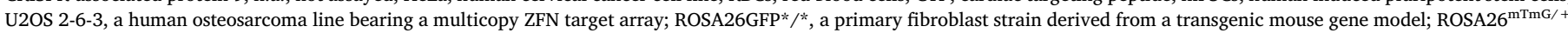

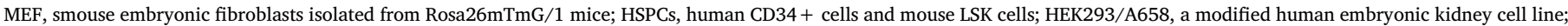

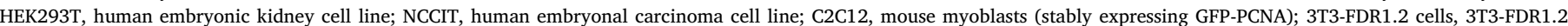

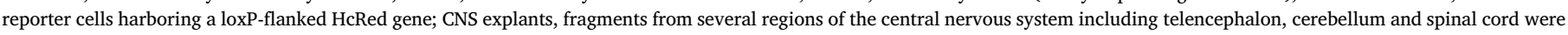
dissected from transgenic embryos or adults and cultured

* Corresponding author at: Laboratory of Biochemistry and Biotechnology, Institute for Marine Science, Federal University of Ceará, Av. da Abolição, 3207, Fortaleza, CE, 60.165-081, Brazil.

** Corresponding author.

E-mail addresses: gandhi.radis@ufc.br, g.radis_baptista@yahoo.com (G. Rádis-Baptista), vicente.freitas@uece.br (V.J.F. Freitas). 
production of cells and tissues for xenotransplant (Liu et al., 2013). Considering these applications, perhaps the most prevalent one is the development of bioreactors, which secrete recombinant protein (biopharmaceuticals) in their fluids (Kues and Niemann, 2004). The traditional methods to obtain transgenic animals are the microinjection of DNA into pronuclear embryos (Gordon and Ruddle, 1981) and the transfection of cells followed by nuclear transfer (Thompson et al., 1989). However, these techniques have several drawbacks, such as the low efficiency of transfection and the reduced development competency of the reconstructed embryo (Houdebine, 2009). Another major disadvantage of the limited use of these techniques in transgenesis is the high cost. The generation of a founder transgenic animal is expected to be around $€ 30-50,000$ depending on the species (Kind and Schnieke, 2008 ) or, more specifically, approximately US $\$ 20,000$ for pigs and US $\$ 250,000$ for cattle (Gama Sosa et al., 2010). Thus far, it is demanding to develop alternative methods that are more efficient and economically affordable. In recent decades, research groups have studied a class of peptides, namely, cell-penetrating peptides (CPPs), which have the ability to translocate across biological membranes and internalize into several kinds of cells. These peptides are additionally capable of carrying distinct types of therapeutic substances, such as low weight hydrophilic molecules (pharmaceuticals and fluorescent probes) and macromolecules, such as proteins and nucleic acids (DNA and RNA), into the cells (Stewart et al., 2008; Koren and Torchilin, 2012). Therefore, a wide range of biomedical and biotechnological uses, especially in gene therapy, has been envisioned, tested and reported for these peptides (Torchilin, 2006; Torchilin, 2008). The ability to form complexes and nanoconjugates with DNA molecules and transduce them to cells, facilitating the insertion of exogenous genes into genomes (Huang et al., 2015), make some CPPs valuable tools in the production of transgenic cells and animals that are useful in the biotechnology, pharmaceutical and livestock industries. The use of CPP-mediated transduction of embryos for animal transgenesis offers some advantages: it overcomes the requirement of micromanipulation, it is less costly (no need for expensive equipment or well-trained personnel) and it is faster (it enables the transfection of several embryos simultaneously) than pronuclear microinjection or nuclear transfer. In addition, with the appearance and development of engineered sitedirected nucleases (ESDNs) to edit genomes, the tendency to use CPPs as transduction agents moves toward the direct delivery of these genome-modifying nucleases into the targeted cells instead of ferrying genes and plasmid DNA vectors by transfection. Within the scope of DNA and protein transduction technology, this review outlines current information and discusses the potential application of CPPs in animal model transgenesis by considering the advancements in the field of this class of bioactive peptides.

\section{Cell-penetrating peptides (CPPs): general concept and classification}

The fast expansion of the field of CPP research and its broad spectrum of applications enable a generalized description of CPPs: they comprise short cationic or amphipathic oligopeptides that have the ability to translocate across the plasma membrane of eukaryotic cells (Pooga and Langel, 2015). In the current literature, CPPs have been referred to as protein transduction domains (PTDs), membrane-permeable peptides (MPPs) or "Trojan horse" peptides. In general, CPPs are small in size and have short amino acid sequences (less than 30 residues) with a high affinity for lipid bilayers; these sequences are responsible for the initial membrane translocation (Lindgren et al., 2000; Regberg et al., 2012, 2013). So far, researchers in the field have attempted also to classify CPPs according to their origin or physicochemical characteristics. In agreement, three categories based on the origin of CPPs can be distinguished: CPPs derived from protein domains, chimeric peptides (formed by the fusion of two natural sequences) and synthetic CPPs (designed sequences based on studies of structure and related activity) (Madani et al., 2011; Bechara and Sagan, 2013; Pooga and Langel, 2015). In terms of their physicochemical characteristics, CPPs can be grouped into three main categories: primary amphipathic, secondary amphipathic, and non-amphipathic CPPs. Primary amphipathic CPPs typically contain hydrophobic and hydrophilic residues along their primary structure. Secondary amphipathic CPPs form an alpha-helix or a beta sheet structure upon interaction with a phospholipid membrane. The non-amphipathic peptides have a high proportion of cationic amino acids (mainly lysine and arginine). CPPs in those categories interact with both natural and anionic lipid membranes, binding preferentially to lipid membranes with a certain content of specific anionic lipids, but enriched in anionic lipids. (Poon and Gariepy, 2007; Ziegler, 2008; Madani et al., 2011). Essentially, the internalization of a CPP basically depends on its amino acid sequence, since its primary and secondary structures impart distinct physicochemical properties, such as amphipathicity, helicity and net (positive) charge, that are essential for interactions with biological membranes and their surface components (Jones and Sayers, 2012; Karagiannis et al., 2013). The intrinsic property of CPPs to permeate across biological membranes has been extensively studied, mainly for utilization in gene therapy, and, therefore, several CPPs have been tested both in vitro and in vivo. In general, the delivery of molecules can occur even if the cargoes have molecular weights that are several times higher than the molecular weight of a given CPP (Lindgren et al., 2000; Hallbrink et al., 2001; Rodrigues et al., 2011). Despite this capability, the CPP-mediated shuttle and delivery efficacy, and even cytotoxicity, invariably depend on the nature of the cargo molecules, among other factors (El-Andaloussi et al., 2007). Moreover, in chimeric proteins fused to CPPs, the efficiency of cell internalization depends on the property of the protein that is conjugated to the CPP, with anionic CPP sequences severely decreasing the cell uptake ability (Matsumoto et al., 2015).

\subsection{CPPs for gene delivery}

The first report for peptides with cell penetration characteristics dates back to the 1980 s, when the penetrating ability of the transactivator of transcription (TAT) of the human immunodeficiency virus type 1 (HIV-1) was observed. Initially, it was found that this viral protein was internalized by cells when present in the culture medium (Frankel and Pabo, 1988). Subsequently, the sequence responsible for the entry into the cell was shown to be restricted to 11 residues (Vives et al., 1997). Moreover, TAT was observed to be internalized by cells in a time- and concentration-dependent manner (Mann and Frankel, 1991). In later decades, several other peptides, such as penetratin from the Antennapedia homeodomain of Drosophila (Derossi et al., 1994), transportan (Pooga et al., 1998) and model amphipathic peptide (MAP) (Oehlke et al., 1998), were prepared and studied for their cellpenetrating properties. TAT and penetratin are included in the group of CPPs with positively charged amino acids, while transportan and MAP are grouped with CPPs displaying a high degree of amphipathicity. One example of a CPP used in gene therapy is the VP22 protein, derived from the herpes simplex virus (Elliott and O'Hare, 1999). This CPP, for instance, was employed as a transducing agent to deliver human papillomavirus E2 fusion-protein and treat HPV-related viral disease. In in vitro assays, VP22-E2 conjugates induced apoptosis in carcinoma and bacterial cell lines, indicating that these cells took up E2 by VP22mediated delivery (Roeder et al., 2004).

Pep-1 was one of the first CPPs used in non-covalent form to deliver proteins, peptides and antibodies into cells to find commercial use, since this short amphipathic peptide was proven to be stable in a physiological buffer, harmless to eukaryotic cells, and active in the presence of serum (Morris et al., 2001). Over the years, an increasing number of peptide sequences that are capable of cellular internalization and the transportation of a variety of cargoes have been described. A handful of CPP sequences, covalently or non-covalently linked nano- 
Table 1

Examples of paradigmatic cell penetrating peptides (CPPs) with their origin, sequence and examples of biotechnological application.

\begin{tabular}{|c|c|c|c|}
\hline СРP & Origin & Peptide sequence and Bio-Pharmaceutical application & Reference \\
\hline \multirow[t]{2}{*}{ TAT } & Protein of HIV-1 & GRKKRRQRRRPQ & Frankel and Pabo, (1988) \\
\hline & & $\begin{array}{l}\text { Molecular imaging; tumor studies and therapy; nanoparticles conjugation; gene } \\
\text { transfer and antisense oligonlucleotide therapy }\end{array}$ & Rizzuti et al. (2015) \\
\hline \multirow[t]{2}{*}{ Penetratin (Antp) } & Third helix of Antennapedia & RQIKIWFQNRRMKWKK & Derossi et al. (1994) \\
\hline & homeodomain of $D$. melanogaster & Transduction of nanoparticles; Bioimaging & Child et al. (2011) \\
\hline \multirow[t]{2}{*}{ Transportan } & Galanine/Mastoparan & GWTLNSAGYLLGKINLKALAALAKKIL & Pooga et al. (1998) \\
\hline & & Delivery of anticancer drugs; tumor studies and therapy & Izabela et al. (2016) \\
\hline \multirow[t]{2}{*}{ MAP } & Synthetic & KLALKLALKALKAALKLA & Oehlke et al. (1998, 2004); \\
\hline & & $\begin{array}{l}\text { deliver of peptide nucleic acids (PNA); antisense oligonucleotide therapy; } \\
\text { intracellular probe }\end{array}$ & Oehlke et al., 1998 \\
\hline \multirow[t]{2}{*}{ Polyarginines } & Based on Tat peptide & Poly-arginine, $(\mathrm{R})_{\mathrm{n}} ; 6<\mathrm{n}<12$ & Mitchell et al. (2000) \\
\hline & & $\begin{array}{l}\text { Functionalization of nanocomplex; transduction of biomolecules; antisense } \\
\text { oligonucelotide therapy }\end{array}$ & Cho et al. (2012) \\
\hline \multirow[t]{2}{*}{ Pep-1 } & HIV-reverse transcriptase/SV40 T- & KETWWETWWTEWSQPKKKRKV & Morris et al. (2001) \\
\hline & antigen & $\begin{array}{l}\text { Transduction of therapeutic proteins; drug delivery; anti-tumor, anti-inflammatory } \\
\text { and anti-neurodegeneration therapy }\end{array}$ & Kim et al. (2015) \\
\hline \multirow[t]{2}{*}{ pVEC } & Cadherin & IRKQAHAHSK & Elmquist et al. (2001) \\
\hline & & $\begin{array}{l}\text { Transport of nucleic acid and streptavidin; sub-cellular compartmentalization and } \\
\text { tracking }\end{array}$ & \\
\hline \multirow[t]{2}{*}{ NrTP } & Crotamine-derived & YKQSHKKGGKKGSG & Rádis-Baptista et al. (2008) \\
\hline & & $\begin{array}{l}\text { Subcellular and Nucleolar homing; transduction of enzymatically active } \beta \text { - } \\
\text { galactosidade }\end{array}$ & Rodrigues et al. (2012) \\
\hline
\end{tabular}

particles, peptides, proteins, small interfering RNA (siRNA), antisense oligonucleotides (asON), double stranded DNA, and even liposomes have consequently been prepared and studied (Koren and Torchilin, 2012; Bechara and Sagan, 2013). As a short summary, Table 1 presents examples of some paradigmatic CPPs used for pharmaceutical development and biotechnological applications. These examples are more classically representative since the listed CPPs, with exception of NrTPs - one of the first class of animal toxin-derived CPPs (Radis-Baptista et al., 2008), established the foundation for CPP-based transduction technology. In fact, the CPPs and their associated transduction technologies have been consolidated as a mature area of Peptide Sciences and Biotechnology, already celebrating more than 20 years of active and fruitful research investigation (Brasseur and Divita, 2010; Bechara and Sagan, 2013). Up to now, almost one thousand CPP sequences have been experimentally validated and maintained in a curated database, as exemplified by the CPPsite database (http://crdd.osdd.net/raghava/ cppsite/) (Agrawal et al., 2016).

In the view of a historical standpoint, another interesting group of CPP sequences are those found in venomous animals, which include natural toxins like crotamine, chlorotoxin and maurocalcine. Advances in the basic research of these venom-derived peptides and the molecular design and engineering of their structures have allowed the generation of derivatives with improved properties, such as short size and efficient cell uptake with concomitant reduction of their noxious/ toxic effects toward healthy cells (Radis-Baptista et al., 2008; Aroui et al., 2009; Akcan et al., 2011; Radis-Baptista and Kerkis, 2011; Tisseyre et al., 2013). Particularly, our group has been working on crotamine and derivatives for animal transgenesis using bovine embryos as a model. Crotamine was first found in the venom of the South American rattlesnake (Goncalves and Polson, 1947). Its cell-penetrating activity was proven in eukaryotic cells (Kerkis et al., 2004; Hayashi et al., 2008). Crotamine also has specificity for tumor and proliferating cells, which makes it an important molecule for antitumor diagnosis and adjuvant therapy as well as cancer research (Kerkis et al., 2010). These additional activities of some CPPs fulfill the concept of so-called theranostic agents or, alternatively, fit in a special class of CPPs, namely, bioportides, which are dualistic CPPs that are intrinsically bioactive (Kerkis et al., 2016). In addition, the ability of crotamine to transfect cells and carry heterologous DNA to various tissues was evidenced (Nascimento et al., 2007) and, currently, different protocols to prepare crotamine-DNA complexes for kinetic studies and gene delivery have been established (Chen et al., 2012a,b; Freitas et al.,
2014). The first report dealing with the translocation of crotamine in mammalian embryos was with mouse morulae (Kerkis et al., 2004). In such study, crotamine was able to translocate across the zona pellucida of embryos and compartmentalize in a population of actively proliferating cells. Recently, our group observed that crotamine also penetrates the zona pellucida of in vitro fertilized bovine embryos (Campelo et al., 2016) - a great advantage for the prospective use of a transduction agent in transgenesis.

\subsection{Mechanisms of CPP-mediated gene delivery}

Electrostatic interactions between CPPs (mainly cationic) and proteoglycans or phospholipids on the cell surface (negatively charged) are considered to be the strong determinant and the general first step of CPP entry into cell (Persson et al., 2001; Nascimento et al., 2007; Poon and Gariepy, 2007; Tiriveedhi and Butko, 2007). Some studies reported the direct involvement of membrane proteoglycans, such as heparan sulfate, in the onset of transduction. In this case, proteoglycans (a variety of anionic cell surface molecules) act as extracellular receptors to internalize exogenous proteins and peptides (Sandgren et al., 2002; Console et al., 2003). However, other studies have shown no correlation between the presence of proteoglycans and membrane translocation (Violini et al., 2002), suggesting that these extracellular receptors have a role to only establish electrostatic interactions between the CPP and the plasma membrane (Mai et al., 2002). Following cell surface interactions, membrane binding and insertion occur, which leads to the direct translocation or endocytosis of CPPs (described in Fig. 1). For one of these processes to occur, some level of amphipathicity (alternate cationic and hydrophobic amino acid residues) in CPP structure is required for membrane insertion (Alves et al., 2008; Eiriksdottir et al., 2010; Walrant et al., 2011). Therefore, a net positive charge and density, hydrogen bonding, and the size and secondary structure of CPPs will drive peptide interactions with different components of the cytoplasmic membranes and, consequently, further internalization into the cells (Bechara and Sagan, 2013; Pooga and Langel, 2015). Currently, a database is available that can help in the prediction of the physicochemical properties of CPPs and compare them with previous experimentally validated peptides (Gautam et al., 2015).

Current experimental data indicates that cell uptake of CPPs occurs through distinct cellular pathways and different routes can operate simultaneously (Fig. 1). Routes such as retrograde transport from early endosomes to the trans-Golgi network (anterograde pathway) and endo- 

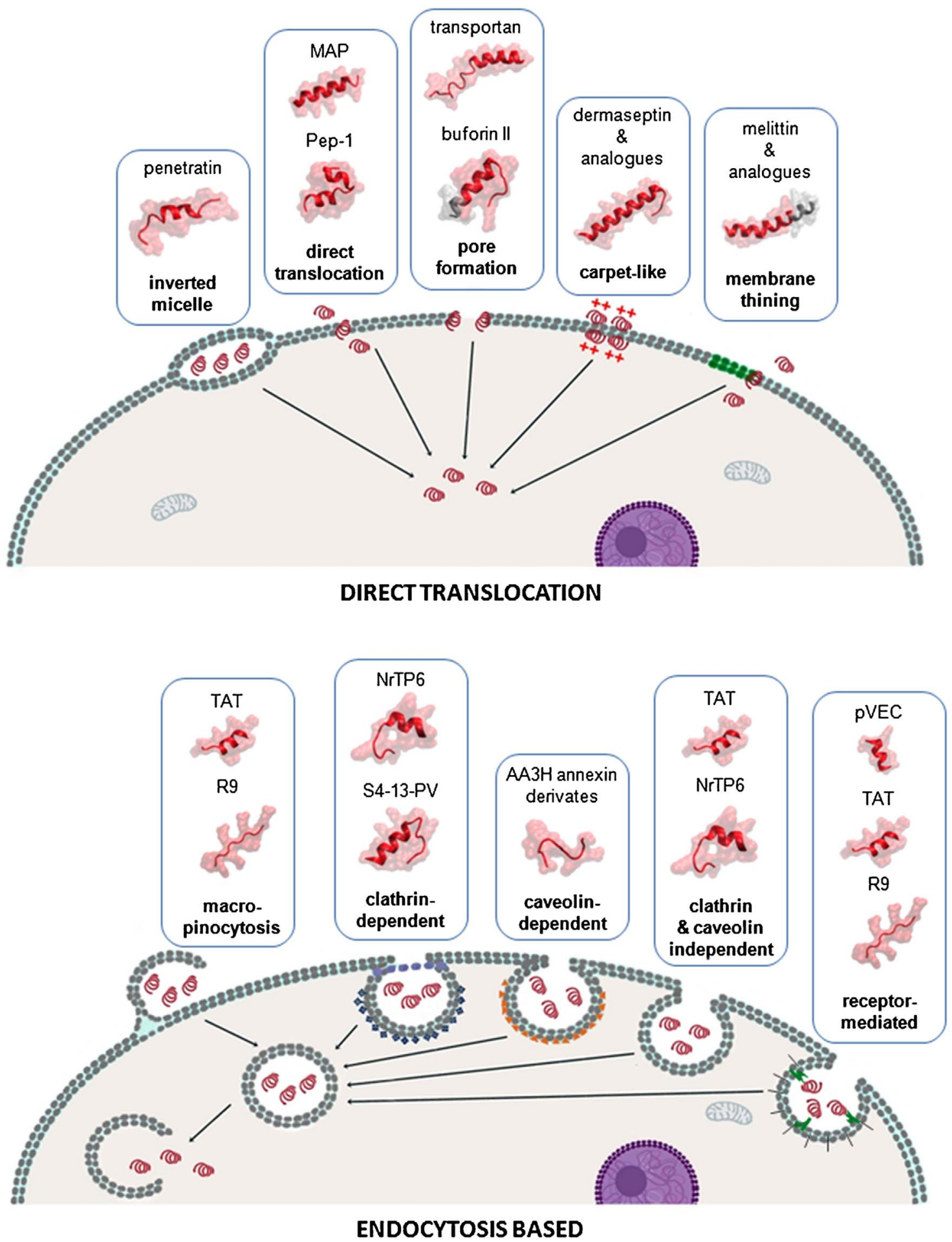

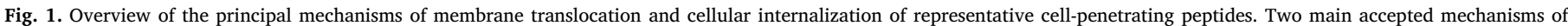

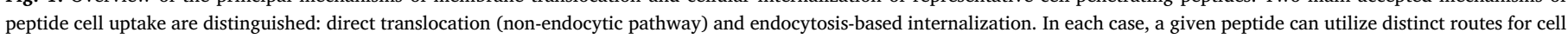

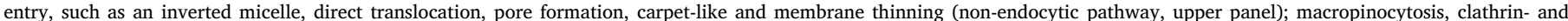

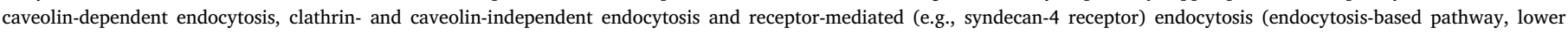

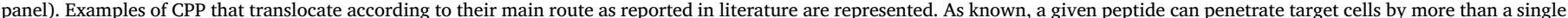
route. CPP structures were retrieved from deposited PDB structures when available, otherwise they were predicted using the PEP-FOLD 3.1 server (Lamiable et al., 2016).

lysosomal pathway are shown to be involved (Fischer et al., 2004; Raagel et al., 2009). However, the detection of CPPs in vitro and in vivo still remains a technical challenge (Qian et al., 2015; Walther et al., 2009). To be visualized on cell membranes and inside cells and organelles, CPPs are usually conjugated to a fluorophore or metal ions for easy detection. This can lead to false-positive results that demand specific probes, such as antibodies, to track CPPs, translocation and internalization.

In general, the mechanism of the internalization of CPPs and their intracellular trafficking varies according to the properties of each peptide, the conjugated molecule, their concentration, action time and the type of target cell (Raagel et al., 2009; Koren and Torchilin, 
2012; Pooga and Langel, 2015). The internalization of TAT, penetratin and transportan, for example, can occur through endocytosis-independent pathways involving the formation of an inverted micelle into the plasma membrane (Derossi et al., 1996; Pooga et al., 1998). Conversely, later studies involving the internalization of TAT demonstrated that the entry of this peptide into the cells occurs via endocytosis, followed by escape in the lysosome and accumulation in the periphery of the nucleus (Caron et al., 2004). The various findings regarding cellular entry have shown that the mechanisms used by CPPs to permeate cells may involve more than a single route. Indeed, at some levels, if one pathway is down-regulated, then one or more alternative routes are upregulated for compensation (Bechara and Sagan, 2013). Overall, one can distinguish various pathways of CPP entry (Fig. 1): (i) inverted micelle formation; (ii) adaptive translocation; (iii) a pore-formation model; (iv) electroporation-like permeabilization; (v) entry at microdomain boundaries; and (vi) endocytosis. In turn, endocytosis can occur via: (i) a classical pathway; (ii) clathrin-mediated endocytosis; (iii) caveolae-mediated uptake; and (iv) macropinocytosis (Stewart et al., 2008; Bechara and Sagan, 2013).

Worthy of mentioning in the view of cargo translocation across membranes, the entry of CPPs into cells by the endocytic pathway can have a detrimental effect on the delivery of cargoes, which could be caused by: hampering and complicating the CPP-cargo's escape from the endosomal compartment, restricting diffusion to the cytosol or promoting complete degradation with the inefficacious transport of cargoes. In combination, these factors eventually lead to a high amount of the CPP vector and respective carrier trapped inside endosomes and a subsequent degradation by lysosomal enzymes (Hallbrink et al., 2001). Some strategies have been developed to overcome this limitation and increase the transduction efficiency. One method consists of covalently linking a sequence of hemagglutinin-2 from the human influenza virus (responsible for lysosomal escape) to the CPP. Upon acidification in the lysosome, the hemagglutinin-2 region is inserted in the lysosomal membrane, forming a pore and allowing the release of the lysosomal contents into the cytosol (Wharton et al., 1988; Nakase et al., 2010). Another method to increase the release of the endosomal contents is the addition of chemical substances in the cell culture medium; in this regard, chloroquine, polyetherimide (PEI) and sucrose are commonly used substances for this purpose. These agents are called lysosomotropic. Chloroquine is a weak base that can enter cells and accumulate in vesicles. At non-toxic concentrations, chloroquine inhibits the acidification of the endosome through the protonation of ions, preventing further entry in the lysosomal pathway. By increasing the concentration, chloroquine ions accumulate, which promotes the swelling and disruption of the endosome (Mellman et al., 1986). By a similar protonation-dependent mechanism, PEI can also interact with the acidic environment of the endosome, leading to swelling and rupture of the membrane. The main disadvantage of using PEI is concerned with its high charge and persistence (non-biodegradability). These characteristics could result in increased toxicity and physiological changes imparted to the proliferating cells (Godbey et al., 2001; Kleemann et al., 2005). Incubating the targeted cells with a high concentration of sucrose is also used as an alternative strategy for promoting the release of the endosomal contents. Sucrose accumulates in the endosomal compartment, leading to swelling and destabilization, followed by extravasation of the content trapped in the endosome (Kato et al., 1984; Abes et al., 2006).

\section{Application of CPP-mediated transduction of antigens and nucleic acids}

Cell-penetrating peptides comprise a suitable alternative to delivery components for the modification of genes, genomes and phenotypes, since CPPs have unique advantages compared to other transduction systems. For instance, although viral vectors have high transduction efficiencies in a variety of cells, the use of these vectors is, in certain circumstances, quite restrictive. Such restrictive use is due to the high risk of the uncontrolled transformation and integration of viral DNA into the host cell genome (Chuah et al., 2003). This drawback is overcome by CPPs, since they have limited toxicity and a relatively high transduction efficiency in eukaryotic cells (Soler et al., 2014). In turn, physical and chemical methods, such as electroporation (Gagne et al., 1991; Mehier-Humbert and Guy, 2005), lipofection (Maurisse et al., 2010) and nanopolymers (Godbey et al., 2001), have low cell specificity, while some CPPs, in contrast, have the tunable ability to selectively permeate specific cell populations (Park et al., 2013).

\subsection{CPP-mediated transduction of antigens and preparation of cellular} vaccines

An example of using CPPs as a non-viral gene delivery system for transduction is the delivery of antigens for the preparation of cellular vaccines. In fact, the preparation of vaccines based on the CPPmediated transduction of antigens and/or their precursors has turned into a very active area of research and development, both for immunotherapy of cancer and infectious diseases (Bae et al., 2016; Wanjale and Kumar, 2016; Yu et al., 2016). In this regard, CPPs are vehicles to shuttle plasmid DNA vectors and antigens to modify the response of immune cells and improve vaccination efficacy (Wang and Wang, 2012; Jiang et al., 2014). For instance, the designed CL22 peptide, which incorporates three protein domains that promote DNA condensation, cleavage by endosomal protease and targeting to the nucleus of recipient cells, was employed to deliver a plasmid encoding tumor-associated antigens (TAAs) and to transfect such vector into dendritic cells (DCs) (Irvine et al., 2000). This CPP forms complexes with plasmid DNA and has a transfection efficiency equivalent to the best available non-viral agents for engineering DCs and, consequently, for preparing vaccines for cellular immunotherapy (Irvine et al., 2000). Cellular-based vaccines have also been prepared by fusing the transduction domain peptide sequence (Z12) of the Epstein-Barr virus ZEBRA protein with multi-epitopic antigens, and they have efficiently delivered the chimeric protein to dendritic cells for cancer immunotherapies (Derouazi et al., 2015). Accordingly, by combining a particular ZEBRACPP sequence with tumor-associated antigens and delivering the fusion protein to a mouse tumor model with a selected adjuvant, a potent antitumor immunity was obtained (Belnoue et al., 2016). Accordingly, the conjugation of CPPs to antigens increases DC uptake, processing and presentation to $\mathrm{CD} 4+$ and $\mathrm{CD} 8+\mathrm{T}$ cells, leading to augmented immune modulation, which is beneficial for cell-based antitumor vaccines (Derouazi et al., 2015; Lim et al., 2016). CPP-antigen based vaccines are also being prepared and tested for the immunotherapy of microbial infection. CPP VP22 was fused to the C-terminal OprF by means of recombinant DNA engineering, and the chimeric protein used for vaccination in a mouse model of Pseudomonas aeruginosa, resulting in potent immune protection compared to DNA vaccines ( $\mathrm{Yu}$ et al., 2016).

\subsection{CPP-mediated transduction to modify protein expression}

Gene therapy is a form of molecular intervention to modify the gene expression of targeted cells for the control of diseases. Currently, gene therapy can be performed either by a classical approach (introduction of a therapeutic gene) or by methods that are based on antisense modulation with small interference RNA (siRNA) and antisense oligonucleotides (asON) (Bennett and Swayze, 2010; Kole et al., 2012). In both approaches to gene therapy, nucleic acid molecules should be delivered into the targeted cells to achieve the desired phenotypic modulation. Since the entry of macromolecules, such negatively charged nucleic acids, is hampered by the plasma membrane, these macromolecules depend on molecular vehicles to permeate the cells and become intracellularly available to exert their actions. Thus, carriers, such as CPPs, can be effectively applied to overcome this 
barrier and promote the internalization of nucleic acid molecules (Lehto et al., 2012). CPPs have been employed as carriers of DNA, siRNA and asON for gene therapy, either as non-covalent complexes or as covalently linked conjugates. However, conjugated peptides may exhibit variable levels of internalization efficiency and the pattern of distribution in living cells may differ among conjugated and nonconjugated peptides (Maiolo et al., 2005). Additionally, one must be aware of the challenges associated with the targeted delivery, stability and detection of cell-penetrating peptides. For example, CPPs may not be very stable in vivo and may need to be rationally and structurally modified (Nielsen et al., 2014; Rennert et al., 2006).

siRNA technology has been used as a new and supportive modality in cancer therapy, and, therefore, molecules of siRNA have been designed to modulate the expression of specific genes (Kanasty et al., 2013). Consequently, CPPs, such as TAT, penetratin (Antp), transportan and some amphipathic CPPs, have been used to shuttle siRNAs (Chiu et al., 2004; Eguchi and Dowdy, 2009). The most widely used CPPs for siRNA delivery, the methods of preparing CPP:siRNA complex condensates (non-covalent) and conjugates (covalent), and the targeted reporter mRNAs tested for the regulation and cancer cells are reviewed elsewhere (Eguchi and Dowdy, 2009; Shukla et al., 2014). The antisense modulation of protein expression using asONs has been very promising to both basic research (to elucidate protein function) and genetic dysfunction (to down-regulate the expression of some clinically relevant proteins) (McClorey and Wood, 2015). Consequently, CPPmediated delivery of asONs has found an application in the treatment of acquired or genetic diseases in humans, as well as in the treatment of microbial infections that can be controlled with antiviral and antibacterial CPP:ON conjugates (Boisguerin et al., 2015). Another means to modify protein expression and the phenotype of cells and tissues using the CPP-delivery of macromolecules relies on the reprogramming and differentiation of induced pluripotent stem (iPS) cells. The technology of iPS cells has tremendous implications in regenerative medicine, and CPPs can be applied in all key steps of genotypic and phenotypic modifications, such as reprogramming, gene editing/correction and differentiation. Again, in these processes, the CPP-mediated protein transduction of transcription factors appears safer than transduction mediated by viral vectors (Kaitsuka and Tomizawa, 2015).

\section{Application of CPPs as transduction agents for modification of genomes}

The CPP-mediated transport of cargo is not only important as an alternative to gene therapy and the intracellular shuttle of antigens; it is also important for research and prospective applications in transgenesis. A number of studies report the transduction of sequences of exogenous DNA in mammalian cells using such class of bioactive peptides, as cited in (Huang et al., 2015). An effective use of CPPs is to deliver functional proteins (or vectors) that are aimed at improving the rate of recombination in experimental transgenesis. Essentially, two major technological strategies are currently employed to modify the genomes of human cells and model organisms, based on CPP-mediated transduction technology. In such technologies, CPPs comprise shuttle moieties for the transduction of a fully active Cre-recombinase or functionally engineered nuclease proteins, which are internalized into cells by CPP sequences that are chemically or biosynthetically conjugated in reference to these specific endonucleases.

\subsection{CPP-mediated transduction of cre recombinase}

The Cre-mediated recombination associated with the cargo-delivery capabilities of CPPs has been used as a proof of concept of genome modification in mammalian cells. In one case, the TAT-Cre-mediated recombination of a loxP-STOP-loxP enhanced green fluorescent protein (EGFP) reporter gene was demonstrated in mouse T cells (tex.loxP.EG) (Wadia et al., 2004). In such a configuration of the Cre-loxP system, exogenous Tat-Cre protein was internalized into the cells and translocated to the nucleus, where it excised the transcriptional "Stop" DNA segment in the cell genome in a nontoxic manner before scoring positive for EGFP expression. Thus, the treatment of target $\mathrm{T}$ cells with transducible TAT-Cre resulted in a site-specific recombination and the subsequent induction of EGFP expression. Moreover, an evident increase in TAT-Cre-mediated recombination was observed by enhancing transduction via endosome disruption, which was assisted by chloroquine treatment or by fusing TAT with the N-terminal of influenza virus hemagglutinin protein (Tat-HA2). Cre-mediated genome modification using CPP-transducible Cre recombinase fusions was demonstrated not only in vitro with several reporter cell lines carrying loxP-flanked ('floxed') genes but also in vivo with transgenic mice (e.g., Rosa $26^{\mathrm{mTmG} / 1}$ mice) and their respective explants as well. For instance, Cre recombinase fused to TAT (hCre-TAT) and hCre-penetratin was readily internalized and transported to the nucleus of transgenic mice cells carrying loxP-flanked genes. The intracellular delivery and cytoplasmic traffic mediated by TAT and penetratin resulted in genomic recombination in subpopulations of neurons in discrete areas of embryonic and adult neural tissues (Gitton et al., 2009). TAT-Cre recombinase fusion protein was also used by Sonsteng et al. (2014) to target hepatocytes in vivo by means of hydrodynamic delivery in transgenic $\left(\mathrm{ROSA}^{\mathrm{nTnG}}\right)$ mice. The transgenic mouse version that they developed localizes the dual red- and green-fluorescent reporter proteins to the nucleus (ROSA ${ }^{\mathrm{nTnG}}$ ) instead of the outer membrane, as originally displayed in mice bearing the ROSA ${ }^{\mathrm{mTmG}}$ genotype, i.e., cells carrying the floxed membrane-targeted tdTomato (tdT) cistron followed by a membrane-targeted, enhanced green fluorescent protein (EGFP) cistron. Thus, using this mouse model of transgenesis, they confirmed that the hydrodynamic delivery of chimeric TAT-Cre fusion protein induces recombination in hepatocytes in vivo, but only in the liver - the targeted organ (Sonsteng et al., 2014). In other study employing mouse embryonic fibroblasts isolated from ROSA26 ${ }^{\mathrm{mTmG}}$ mice, Chien et al. (2014) demonstrated that both Cre-Antp and Cre-CTP efficiently caused recombination in vitro, and Cre-CTP activity was four times that observed with Cre-Antp. These recombinant Cre-CPP recombinase proteins were prepared by fusing, in frame, the C-terminal of Cre with antennapedia (Antp, RQIKIQFQNRRKWKK) and cardiovascular targeting peptide (APWHLSSQYSRT); this result was discovered later by screening a phage display library. Moreover, an in vivo injection of Cre-Antp and Cre-CTP proteins in skeletal and cardiac muscle promoted recombination and scored positive for genome modification in ROSA26 ${ }^{\mathrm{mTmG}}$ myocytes and in ROSA26 LacZ mouse hearts (Chien et al., 2014).

As reported, TAT fused to the N-terminal of Cre recombinase is not the only configuration that imparts cell permeability to the CPP-fusion proteins; other CPP moieties that are alternatively linked to N- or Cterminal have served the delivery of this class of recombinases. For instance, DPV-Cre and GET-Cre (P21-mR-Cre-8R) fusion proteins illustrate the diversification of CPPs that make Cre recombinase transducible. DPVs (Diatos peptide vectors) originate from human heparin binding proteins and/or anti-DNA antibodies. Their sequences were fused to the $\mathrm{N}$-terminal of Cre recombinase via molecular cloning, and recombinant chimeric DPV-Cre protein was utilized to drive LoxP recombination in HEK-293 cells that carried an integrated LoxP-EGFP reporter construct (De Coupade et al., 2005). The GET-Cre (P21-mRCre-8R) configuration relied on the fusion of a membrane-docking peptide to heparan sulfate glycosaminoglycans (GAGs), namely, P21, to the N-terminal of Cre recombinase and was fused to red fluorescent protein (mR), and octa-arginine (8R) was fused at the C-terminal. GETCre enhanced the intracellular delivery of Cre in a very short period of time and elicited Cre-mediated genome modification in NIH3T3 mouse fibroblast (NIH3T3:LSL-eGFP) reporter cells (Dixon et al., 2016). Another former example of Cre-CPP transducible protein is Cre-MTS, in which the 12-amino acid membrane translocation sequence (MTS, AAVLLPVLLAAP) was derived from the Kaposi fibroblast growth factor 
Table 2

Selected examples of CPP-mediated intracellular delivery of functional components for site-specific modification of genomes.

\begin{tabular}{|c|c|c|c|c|}
\hline $\begin{array}{l}\text { Genome editing } \\
\text { technology }\end{array}$ & $\begin{array}{l}\text { Transduction system } \\
\text { component }\end{array}$ & Cell-penetrating peptide moiety & Main cell types & Reference \\
\hline \multirow[t]{10}{*}{ Cre-recombinase } & \multicolumn{4}{|l|}{$\begin{array}{l}\text { (Recombinant fusion } \\
\text { proteins) }\end{array}$} \\
\hline & Cre-MTS & MTS/FGF4 (AAVLLPVLLAAP) & All cells/ROSA26 mice & Jo et al. (2001) \\
\hline & TAT-Cre & TAT & NIH3T3 loxP.LacZ & Wadia et al. (2004) \\
\hline & DPV-Cre & Diatos peptides & HEK-293 (LoxP-EGFP) & De Coupade et al. (2005) \\
\hline & TAT-Cre & TAT & HeLa (Rep250) & Hashimoto et al. (2008) \\
\hline & TAT-Cre & TAT & transgenic goat fibroblast & Xu et al. (2008) \\
\hline & $\begin{array}{l}\text { Penetratin-Cre and TAT- } \\
\text { Cre }\end{array}$ & Antp and TAT & CNS explants & Gitton et al. (2009) \\
\hline & TAT-Cre & TAT & ROSA $^{\mathrm{nT2nG}}$ hepatocytes & Sonsteng et al. (2014) \\
\hline & Cre-CTP and Cre-Antp & Antp and CTP (APWHLSSQYSRT) & ROSA $26^{\mathrm{mTmG} /+}$ MEFs & Chien et al. (2014) \\
\hline & GET-Cre (P21-mR-Cre-8R) & $\begin{array}{l}\text { P21 (KRKKKGKGLGKKRDPCLRKYK) and octa-arginine } \\
\text { (8R) }\end{array}$ & NIH3T3 (LSP-eGFP cells) & Dixon et al. (2016) \\
\hline Targeted nucleases & \multicolumn{4}{|l|}{ (Fusions or conjugates) } \\
\hline \multirow[t]{2}{*}{ ZFN } & TAT-ZFN fusion proteins & TAT (YGRKKRRQRRR) & n.a. & Ru et al. (2013) \\
\hline & $\begin{array}{l}\text { transferrin-ZFN } \\
\text { conjugates }\end{array}$ & Transferrin & $\begin{array}{l}\text { HEK293/A658, U2OS 2-6-3, } \\
\text { ROSA2 }^{\text {GFP*/* }} \text { and HSPCs }\end{array}$ & Chen et al. (2013) \\
\hline \multirow[t]{2}{*}{ TALENs } & $\begin{array}{l}\text { TAT-TALEN fusion } \\
\text { proteins }\end{array}$ & TAT (YGRKKRRQRRR) & HeLa and hiPSCs & Ru et al. (2013) \\
\hline & R9-conjugated TALENs & nona-arginine (9R) & HeLa and HEK293 & Liu et al. (2014) \\
\hline CRISPR/Cas9 & $\begin{array}{l}\text { Cas9-mR9 chimeric } \\
\text { protein/ } \\
\text { sgRNA:mR9 complex }\end{array}$ & nona-arginine $(9 \mathrm{R})$ & HeLa, HEK293T, and NCCIT & $\begin{array}{l}\text { Ramakrishna et al. } \\
\text { (2014) }\end{array}$ \\
\hline
\end{tabular}

(FGF-4). The intra-peritoneal injection of mice (ROSA26/LacZ) with transducible Cre-MTS induced systemic recombination, as demonstrated by the expression of $\beta$-galactosidase in all examined organs, including the brain (Jo et al., 2001). Interestingly, Hashimoto and coworkers (Hashimoto et al., 2008) demonstrated that Cre-mediated recombination induced by transducible TAT-Cre recombinase occurred preferentially and with higher frequency in mammalian cells that were in the S-phase of the cell cycle, and this fact appears to be advantageous to the in vivo use of the Cre/loxP site-specific recombination system together with transiently active and transducible CPP-Cre recombinase. In Table 2, engineered, cell-permeable CPP-Cre recombinase fusion proteins are indicated as well as the cell and tissue types that are targeted for genome modification.

\subsection{CPP-mediated transduction of ZFNs, TALENs and CRISPR-associated protein 9}

The engineered site-directed nucleases, such as meganucleases, zinc finger nucleases (ZFNs), transcription activator-like (TAL) effector nucleases (TALENs), and the clustered regularly interspaced short palindromic repeat-associated nuclease Cas9 (CRISPR/Cas9), provided cutting edge technologies for manipulating genes and genomes of virtually any organism. These programmed nucleases, once inside the cell, incise genomic DNA at specific sites, generating double-strand breaks (DSBs) that are repaired through natural, non-homologous endjoining (NHEJ) or homology-directed repair (HDR) systems, by which the genomes of cells and organisms are modified by cutting and pasting of genetic information (Kim, 2016). Such technologies for genome modification or genome editing with engineered nucleases are currently entering a pipeline to generate transgenic animals and plants derived from economically important species. The modification of genetic traits in animals, as aforementioned, aims to improve end-products (e.g., nonallergenic milk; increases in meat production), promote resistance to pathogens and diseases, and change tissue epitopes to avoid immune rejection in organs for xenotransplantation (reviewed in Sovová et al., 2017), (Sovova et al., 2016). Experimentally, to generate transgenic cells and organisms using ESDNs, such as ZFNs and TALENs, the cells are either transfected by electroporation with recombinant plasmids carrying encoding nuclease protein sequences or are transduced by engineered viral vectors carrying RNA-guided nuclease components, such as those from the CRISPR/Cas9 nuclease platform (Cai et al., 2014; Maggio et al., 2014; Matsubara et al., 2014). Additionally, it was determined that purified ZFN proteins are intrinsically cell-penetrating and therefore can directly self-internalize into targeted cells and produce double-strand breaks in genomic DNA (Gaj et al., 2012). Indeed, the efficient delivery of ESDNs is one of the major factors that influences the frequency of targeted integration of a given genetic trait of a modified genome. In fact, receptor-mediated endocytosis of engineered ZFN conjugated with the transferring moiety improved the cell-penetrating capabilities of ZFN and the efficiency of genome modification in human and mouse stem-progenitor cells (Chen et al., 2012a,b, 2013) The delivery of engineered nucleases using CPPmediated internalization has advantages over the transduction or transfection of vector-mediated cDNAs or RNAs encoding ESDNs; in the CPP transduction technology, prolonged and uncontrolled nuclease expression, which potentially increases the off-target genome excision effect and high toxicity, are prevented or diminished (Pruett-Miller et al., 2009; Ru et al., 2013).

Another successful case of CPP-mediated delivery of ESDNs is exemplified by the efficient cellular uptake of TALENs conjugated to poly-Arg CPP via the Cys residues that are exposed on the surface of each TAL effector repeat (Liu et al., 2014). Interestingly, the conjugation of poly-Arg CPPs to individual TAL effectors was ingeniously reversible under the reducing conditions of the cell cytoplasm, enabling cargo release and TALEN-mediated gene modification in mammalian cells (Liu et al., 2014). Cell-penetrating peptides have also served to deliver RNA-guided endonucleases (RGENs) derived from the CRISPR/ Cas 9 system. In a recent report, a recombinant Cas 9 protein was conjugated via the Cys-terminal residue to poly-Arg, i.e., nine arginine residues (9R), resulting in a cell-permeable Cas9-mR9 chimeric protein that was applied, in combination with a molecular complex formed by single guide-RNA and poly-Arg (sgRNA:9R), to modify the genome of several human cell types with a reduced off-target incision effect (Ramakrishna et al., 2014). These and other selected examples of CPP-mediated delivery of functional proteins for site-specific genomic modification to introduce new traits in some target cells are shown in Table 2. In Fig. 2, hypothetical Cas9 proteins that are fused to a nucleolar targeting peptide (NrTP) or Tat at the N-terminal and Cterminal, respectively, are illustrated. The strategies that could be used to deliver components of the CRISPR/Cas9 genome editing system via 


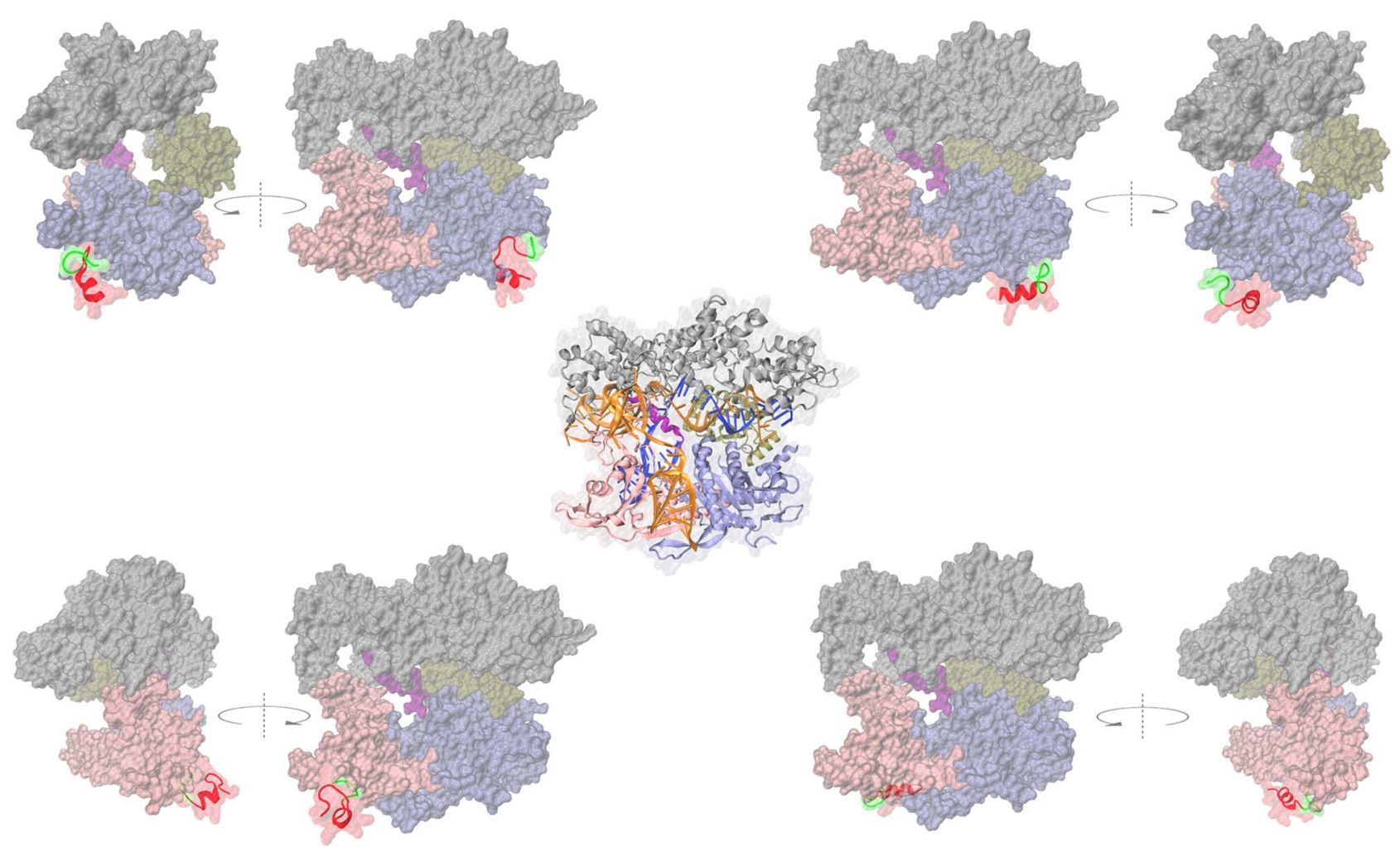

Fig. 2. Designed N- and C-terminal fusion proteins of Cas9 nuclease and representative CPPs (NrTP and Tat). Center, the crystal structure of the CRISPR-associated endonuclease Cas9 from Streptococcus pyogenes (PDB:4UN3, resolution of $2.59 \AA$ Å) was used to predict the structures of our hypothetical Cas9-TAT and Cas9-NrTP fusion proteins. Cas9 domains are colored in ice blue for RuvC, in purple for the arginine-rich motif (ARM), in silver for the recognition lobe (REC), in tan for the HNH domain, and in pink for the PAM-interacting domain (PI). Topleft, NrTP-Cas9 fusion. Top-right, TAT-Cas9 fusion. Bottom-left, Cas9-NrTP fusion. Bottom-right, Cas9-TAT fusion. For each CPP-Cas9 fusion model, the extra G-link and CPP (TAT or NrTP) are visible in green and red, respectively. The structures of the CPP with the G-link were predicted using the PEP-FOLD 3.1 server (Lamiable et al., 2016). In the case of the Cas9NrTP, Cas9-TAT, and NrTP-Cas9 fusions, the predictions were performed with an extra Cas9 overlap region of 23-27 AA and were used to position and orientate the CPP_G-link structure. The overlap was done in VMD 1.9.3 (Humphrey et al., 1996) with a root-mean-square deviation of atomic positions (RMSD) between 1.09 and 1.97. Regarding the TAT-Cas9 fusion, we could not achieve a correct overlap structure; thus, the TAT_G-link was linked using the Join Models feature available in Chimera 1.11.2 (Pettersen et al., 2004). All models are rendered in VMD using Tachyon (Stone, 1998). (For interpretation of the references to colour in this figure legend, the reader is referred to the web version of this article.)
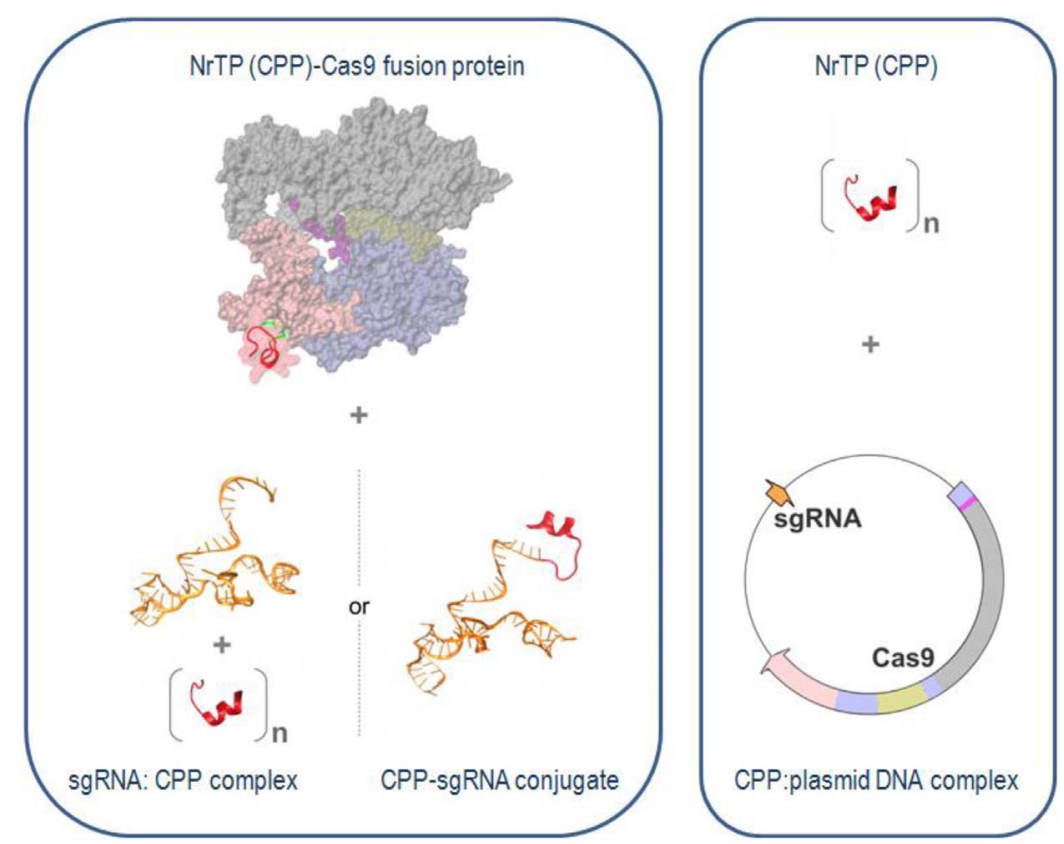

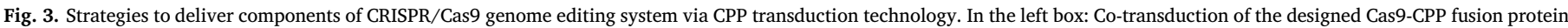

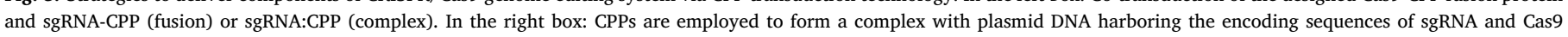

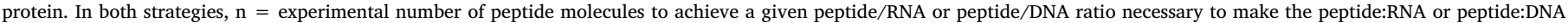

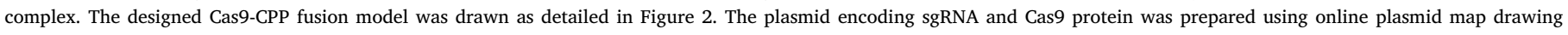
application Savvy version 0.1 (http://www.bioinformatics.org/savvy/). 
CPP transduction technology are depicted in Fig. 3. These strategies essentially comprise either the co-transduction of Cas9-CPP fusion protein and sgRNA-CPP (in their fusion configuration or a peptideRNA complex) or the CPP-mediated delivery of DNA plasmids harboring the encoding sequences of sgRNA and Cas9 protein.

\section{Prospective application of CPPs in animal model of transgenesis}

Although limited examples of genome modification using the abovementioned editing technologies are presently reported in cell types and tissues other than those from humans and mice, the application of transducible Cre-CPP functional proteins for the sitespecific genome modification of economically important animals was demonstrated in the domestic goat (Xu et al., 2008). Therein, fibroblast cells from BLG transgenic goats, which express human lysozyme in their milk and harbor a LNTL vector, contained a neomycin resistance gene (Neo) and a thymidine kinase gene (TK) flanked by loxP sites. These cells were treated with a transducible Cre-TAT recombinase that specifically removed the selectable genes (Neo-TK cassette). The nucleus of these TAT-Cre-treated fibroblast cells were then used for nuclear transfer with the aim of reconstructing new transgenic goat embryos. The results of this study proved that CPP-Cre-mediated sitespecific recombination did not affect the development competency and reconstruction of embryos.

In addition, the transduction of functional proteins has also been demonstrated in non-mammalian animal species, such as zebrafish, and commercially important crustaceans, such as shrimp. For instance, in zebrafish (Danio rerio), when poly-arginine (9R) and transportan were conjugated to fluorescent probes and used in combination with cerebroventricular microinjection-based translocation, they were shown to penetrate into deep brain tissues and home into radial glial progenitor cells - a cellular niche that is responsible for neurogenesis in adults (Kizil et al., 2015). Moreover, 9R-CPP transduced into the brain tissue a plasmid that was conjugated to the carrier peptide by copper-free click chemistry. Neural cells far from the ventricular surface expressed the GFP reporter gene after CVMI of the peptide-tagged plasmid. These findings were useful to confirm the cargo delivery capabilities of CPP in the neural tissue of a model fish and to track the intracellular transport of compounds for neurodegeneration - an issue that has implications in the field of tissue engineering.

In the penaeid shrimp Litopenaeus schmitti, a CPP:DNA complex formed by the SV40 T antigen nuclear localization sequence (NLS) peptide (CGGPKKKRKVG-amide) non-covalently bound to a plasmid vector that contains the tilapia growth hormone gene (tiGH) was used to electroporate shrimp zygotes with an efficiency that reached over $30 \%$ (Arenal et al., 2008). This combination of techniques demonstrated that NLS peptides, which share some structural and physicochemical properties with CPPs, once conjugated with transgene constructs, facilitated the mass transfection of shrimp embryos and precluded the mosaic formation of this rapidly developing species of crustaceans. In another shrimp species, the economically important Pacific whiteleg shrimp L. vannamei, a recombinant chimeric protein engineered with TAT peptide and the multifunctional protein fortlin improved the trans-membrane transportation efficiency of fortlin and induced an augmented hemocyte immune response in shrimp Zhou et al. (2012). In the same line, CPPs, such as Antennapedia (Antp) and TAT, were fused to the $\mathrm{N}$ - or C-terminus of Sia10, a protective antigen of Streptococcus iniae, and used in the vaccination of Japanese flounder fish (Paralichthys olivaceus). The transduction of rTat-Sia10 into the head kidney lymphocytes and gill cells of $P$. olivaceus significantly enhanced macrophage activation and peripheral blood leukocyte proliferation and, consequently, induced a potent immune response, thus, confirming the feasibility of protein transduction technology in animal immunotherapy (Sun and Hu, 2015). Finally, as a model of transgenesis in insects, Sf9 (Spodoptera frugiperda) fall armyworm cells were efficiently transduced with non-covalent complexes of plasmid DNA carrying reporter genes and arginine-rich CPPs, such nona-arginine (R9) and histidine-rich nona-arginine (HR9; C-5H-R9-5H-C). The CPP:DNA complexes were not cytotoxic and the expression of transgenes could be assessed at the protein and mRNA levels. (Chen et al., 2012a,b)

\section{Conclusions}

The versatility of CPPs is remarkable, owing to their capacity to form a complex and to deliver efficiently a wide range of exogenous macromolecules, including nucleic acids and proteins, into target cells. Apart from forming non-covalent complexes with nucleic acids, CPPs are also amenable to chemical conjugation with oligonucleotides and can be fused to proteins by recombinant DNA technology without appreciable loss of their transduction function. Such versatility is important for different technological platforms that are aimed at the modification of protein expression and genome editing. CPPs are employed to deliver antisense oligonucleotides that have applications in the regulation of mRNA/protein expression in the pathological conditions of genetic-based and infectious diseases. CPP-mediated transduction is also currently employed to produce potent cellular vaccines to treat human cancer and to improve resistance to infection in farming animals. The fusion of CPPs to functionally active enzymes via conjugation (by chemically coupling protein and CPP moieties or by recombinant protein engineering) has produced transducible (cell permeable) nucleases that have substantially improved the rate of recombination; this has consequently opened a window of possibilities in animal transgenesis for biotechnological purposes and for the production of biopharmaceuticals. Various examples of genome modification were presented here. Although they are limited due to their relative novelty and experimental challenges, they offer solid evidence that supports the applicability of CPP-transduction technology for the delivery of chimeric CPP-ESDNs into target cells and tissues. The transient activity of functionally active nucleases inside the targeted cells, as delivered by CPPs, is, in practice, more advantageous for genome modification than expressing the nuclease gene from a delivered vector. The intracellular delivery of purified recombinant CPP-nuclease chimeras rather than nuclease gene packages (e.g., by viral vector or CPP-mediated delivery) exhibits a short onset of action and rapid turnover as well as potentially reducing off-target effects in the process of editing genes and genomes. In this scenario, the animal transgenesis can rely on the use of CPP-mediated transduction of RGENs to modify genomes for the production of high value food, as well as tissues and organs for xenotransplantation and biopharmaceuticals.

\section{Acknowledgments}

The authors are grateful to the following federal Brazilian funding agencies: the Coordination for the Improvement of Higher Education Personnel (CAPES), the Ministry of Education (ME) and the Brazilian National Council for Scientific and Technological Development, the Ministry of Science, Technology and Innovation (MCTI); and the State Agency, FUNCAP/PRONEX (grant \# PR2-010100059-01-00/15).

\section{References}

Abes, S., Williams, D., Prevot, P., Thierry, A., Gait, M.J., Lebleu, B., 2006. Endosome trapping limits the efficiency of splicing correction by PNA-oligolysine conjugates. J. Control. Release 110, 595-604.

Agrawal, P., Bhalla, S., Usmani, S.S., Singh, S., Chaudhary, K., Raghava, G.P., Gautam, A., 2016. CPPsite 2.0: a repository of experimentally validated cell-penetrating peptides. Nucleic Acids Res. 44, D1098-D1103.

Akcan, M., Stroud, M.R., Hansen, S.J., Clark, R.J., Daly, N.L., Craik, D.J., Olson, J.M., 2011. Chemical re-engineering of chlorotoxin improves bioconjugation properties for tumor imaging and targeted therapy. J. Med. Chem. 54, 782-787.

Alves, I.D., Goasdoue, N., Correia, I., Aubry, S., Galanth, C., Sagan, S., Lavielle, S. Chassaing, G., 2008. Membrane interaction and perturbation mechanisms induced by two cationic cell penetrating peptides with distinct charge distribution. Biochim. 
Biophys. Acta 94, 8-959.

Arenal, A., Pimentel, R., Pimentel, E., Martin, L., Santiesteban, D., Franco, R., Alestrom, P., 2008. Growth enhancement of shrimp (Litopenaeus schmitti) after transfer of tilapia growth hormone gene. Biotechnol. Lett. 30, 845-851.

Aroui, S., Ram, N., Appaix, F., Ronjat, M., Kenani, A., Pirollet, F., De Waard, M., 2009. Maurocalcine as a non toxic drug carrier overcomes doxorubicin resistance in the cancer cell line MDA-MB 231. Pharm. Res. 26, 836-845.

Bae, H.D., Lee, J., Jin, X.H., Lee, K., 2016. Potential of translationally controlled tumor protein-derived protein transduction domains as antigen carriers for nasal vaccine delivery. Mol. Pharm. 13, 3196-3205.

Bechara, C., Sagan, S., 2013. Cell-penetrating peptides: 20 years later, where do we stand? FEBS Lett. 587, 1693-1702.

Belnoue, E., Di Berardino-Besson, W., Gaertner, H., et al., 2016. Enhancing antitumor immune responses by optimized combinations of cell-penetrating peptide-based vaccines and adjuvants. Mole. Ther. 24, 1675-1685.

Bennett, C.F., Swayze, E.E., 2010. RNA targeting therapeutics: molecular mechanisms of antisense oligonucleotides as a therapeutic platform. Annu. Rev. Pharmacool. Toxicol. 50, 259-293.

Boisguerin, P., Deshayes, S., Gait, M.J., O'Donovan, L., Godfrey, C., Betts, C.A., Wood, M.J., Lebleu, B., 2015. Delivery of therapeutic oligonucleotides with cell penetrating peptides. Adv. Drug Deliv. Rev. 87, 52-67.

Brasseur, R., Divita, G., 2010. Happy birthday cell penetrating peptides: already 20 years. Biochim. Biophys. Acta 217, 2177-2181.

Cai, Y., Bak, R.O., Mikkelsen, J.G., 2014. Targeted genome editing by lentiviral protein transduction of zinc-finger and TAL-effector nucleases. Elife 3, e01911.

Campelo, I.S., Pereira, A.F., Alcantara-Neto, A.S., et al., 2016. Effect of crotamine, a cellpenetrating peptide, on blastocyst production and gene expression of in vitro fertilized bovine embryos. Zygote (Cambridge, England) 24, 48-57.

Caron, N.J., Quenneville, S.P., Tremblay, J.P., 2004. Endosome disruption enhances the functional nuclear delivery of Tat-fusion proteins. Biochem. Biophys. Res. Commun. 319, 12-20.

Chen, P.C., Hayashi, M.A., Oliveira, E.B., Karpel, R.L., 2012a. DNA-interactive properties of crotamine, a cell-penetrating polypeptide and a potential drug carrier. PLoS One 7, e48913.

Chen, Y.J., Liu, B.R., Dai, Y.H., Lee, C.Y., Chan, M.H., Chen, H.H., Chiang, H.J., Lee, H.J., 2012b. A gene delivery system for insect cells mediated by arginine-rich cellpenetrating peptides. Gene 493, 201-210.

Chen, Z., Jaafar, L., Agyekum, D.G., et al., 2013. Receptor-mediated delivery of engineered nucleases for genome modification. Nucleic Acids Res. 41, e182.

Chien, W.M., Liu, Y., Chin, M.T., 2014. Genomic DNA recombination with cellpenetrating peptide-tagged cre protein in mouse skeletal and cardiac muscle. Genesis 52, 695-701.

Child, H.W., Del Pino, P.A., De La Fuente, J.M., Hursthouse, A.S., Stirling, D., Mullen, M., McPhee, G.M., Nixon, C., Jayawarna, V., Berry, C.C., 2011. Working together: the combined application of a magnetic field and penetratin for the delivery of magnetic nanoparticles to cells in 3D. ACS Nano 5, 7910-7919.

Chiu, Y.L., Ali, A., Chu, C.Y., Cao, H., Rana, T.M., 2004. Visualizing a correlation between siRNA localization, cellular uptake, and RNAi in living cells. Chem. Biol. 11, 1165-1175.

Cho, H.J., Chong, S., Chung, S.J., Shim, C.K., Kim, D.D., 2012. Poly-L-arginine and dextran sulfate-based nanocomplex for epidermal growth factor receptor (EGFR) siRNA delivery: its application for head and neck cancer treatment. Pharm. Res. 29, 1007-1019.

Chuah, M.K., Collen, D., VandenDriessche, T., 2003. Biosafety of adenoviral vectors. Curr. Gene Ther. 3, 527-543.

Console, S., Marty, C., Garcia-Echeverria, C., Schwendener, R., Ballmer-Hofer, K., 2003. Antennapedia and HIV transactivator of transcription (TAT) protein transduction domains promote endocytosis of high molecular weight cargo upon binding to cell surface glycosaminoglycans. J. Biol. Chem. 278, 35109-35114.

De Coupade, C., Fittipaldi, A., Chagnas, V., et al., 2005. Novel human-derived cellpenetrating peptides for specific subcellular delivery of therapeutic biomolecules. Biochem. J 390, 407-418.

Derossi, D., Joliot, A.H., Chassaing, G., Prochiantz, A., 1994. The third helix of the Antennapedia homeodomain translocates through biological membranes. J. Biol. Chem. 269, 10444-10450.

Derossi, D., Calvet, S., Trembleau, A., Brunissen, A., Chassaing, G., Prochiantz, A., 1996. Cell internalization of the third helix of the Antennapedia homeodomain is receptorindependent. J. Biol. Chem. 271, 18188-18193.

Derouazi, M., Di Berardino-Besson, W., Belnoue, E., et al., 2015. Novel cell-penetrating peptide-based vaccine induces robust CD4 + and CD8 + T cell-mediated antitumor immunity. Cancer Res. 75, 3020-3031.

Dixon, J.E., Osman, G., Morris, G.E., Markides, H., Rotherham, M., Bayoussef, Z., El Haj, A.J., Denning, C., Shakesheff, K.M., 2016. Highly efficient delivery of functional cargoes by the synergistic effect of GAG binding motifs and cell-penetrating peptides. Proc. Natl. Acad. Sci. U. S. A. 113, E291-299.

Ebert, K.M., Selgrath, J.P., DiTullio, P., Denman, J., Smith, T.E., Memon, M.A., Schindler, J.E., Monastersky, G.M., Vitale, J.A., Gordon, K., 1991. Transgenic production of a variant of human tissue-type plasminogen activator in goat milk: generation of transgenic goats and analysis of expression. Biotechnology (N.Y.) 9, 835-838.

Eguchi, A., Dowdy, S.F., 2009. siRNA delivery using peptide transduction domains. Trends Pharmacol. Sci. 30, 341-345.

Eiriksdottir, E., Konate, K., Langel, U., Divita, G., Deshayes, S., 2010. Secondary structure of cell-penetrating peptides controls membrane interaction and insertion. Biochim. Biophys. Acta 1798, 9-1128.

El-Andaloussi, S., Jarver, P., Johansson, H.J., Langel, U., 2007. Cargo-dependent cytotoxicity and delivery efficacy of cell-penetrating peptides: a comparative study.
Biochem. J. 407, 285-292.

Elliott, G., O'Hare, P., 1999. Intercellular trafficking of VP22-GFP fusion proteins. Gene Ther. 6, 149-151.

Fan, J., Kitajima, S., Watanabe, T., Xu, J., Zhang, J., Liu, E., Chen, Y.E., 2015. Rabbit models for the study of human atherosclerosis: from pathophysiological mechanisms to translational medicine. Pharmacol. Ther. 146, 104-119.

Fischer, R., Kohler, K., Fotin-Mleczek, M., Brock, R., 2004. A stepwise dissection of the intracellular fate of cationic cell-penetrating peptides. J. Biol. Chem. 279, 12625-12635.

Frankel, A.D., Pabo, C.O., 1988. Cellular uptake of the tat protein from human immunodeficiency virus. Cell 55, 1189-1193.

Freitas, V.J.F., Serova, I.A., Moura, R.R., et al., 2012. The establishment of two transgenic goat lines for mammary gland hG-CSF expression. Small Rumin. Res. 105, 105-113.

Freitas, V.J.F., Alcântara-Neto, A.S., Pereira, A.F., Campelo, I.S., Melo, L.M., RádisBaptista, G., 2014. Assessing the complex formation between crotamine - a natural cell penetrating peptide - and DNA using high sensitive fluorescence exclusion assay. Cloning Transgenes 3, 1-5.

Gagne, M.B., Pothier, F., Sirard, M.A., 1991. Electroporation of bovine spermatozoa to carry foreign DNA in oocytes. Mol. Reprod. Dev. 29, 6-15.

Gaj, T., Guo, J., Kato, Y., Sirk, S.J., Barbas 3rd, C.F., 2012. Targeted gene knockout by direct delivery of zinc-finger nuclease proteins. Nat. Methods 9, 805-807.

Gama Sosa, M.A., De Gasperi, R., Elder, G.A., 2010. Animal transgenesis: an overview. Brain Struct. Funct. 214, 91-109.

Gautam, A., Chaudhary, K., Kumar, R., Raghava, G.P., 2015. Computer-Aided virtual screening and designing of cell-penetrating peptides. Methods Mol. Biol. (Clifton, NJ) 1324, 59-69.

Gitton, Y., Tibaldi, L., Dupont, E., Levi, G., Joliot, A., 2009. Efficient CPP-mediated Cre protein delivery to developing and adult CNS tissues. BMC Biotechnol. 9, 40.

Godbey, W.T., Wu, K.K., Mikos, A.G., 2001. Poly(ethylenimine)-mediated gene delivery affects endothelial cell function and viability. Biomaterials 22, 471-480.

Goncalves, J.M., Polson, A., 1947. The electrophoretic analysis of snake venoms. Arch. Biochem. 13, 253-259.

Gordon, J.W., Ruddle, F.H., 1981. Integration and stable germ line transmission of genes injected into mouse pronuclei. Science (New York, NY) 214, 1244-1246.

Hallbrink, M., Floren, A., Elmquist, A., Pooga, M., Bartfai, T., Langel, U., 2001. Cargo delivery kinetics of cell-penetrating peptides. Biochim. Biophys. Acta 1515, 101-109.

Hashimoto, M., Taniguchi, M., Yoshino, S., Arai, S., Sato, K., 2008. S Phase-preferential Cre-recombination in mammalian cells revealed by HIV-TAT-PTD-mediated protein transduction. J. Biochem. 143, 87-95.

Hayashi, M.A., Nascimento, F.D., Kerkis, A., et al., 2008. Cytotoxic effects of crotamine are mediated through lysosomal membrane permeabilization. Toxicon 52, 508-517.

Houdebine, L.M., 2009. Production of pharmaceutical proteins by transgenic animals. Comp. Immunol. Microbiol. Infect. Dis. 32, 107-121.

Huang, Y.W., Lee, H.J., Tolliver, L.M., Aronstam, R.S., 2015. Delivery of nucleic acids and nanomaterials by cell-penetrating peptides: opportunities and challenges. BioMed Res. Int. 2015, 834079.

Humphrey, W., Dalke, A., Schulten, K., 1996. VMD: visual molecular dynamics. J. Mol. Graph. 14 (33-38), 27-38.

Irvine, A.S., Trinder, P.K., Laughton, D.L., et al., 2000. Efficient nonviral transfection of dendritic cells and their use for in vivo immunization. Nat. Biotechnol. 18, 1273-1278.

Izabela, R., Jarosław, R., Magdalena, A., Piotr, R., Ivan, K., 2016. Transportan 10 improves the anticancer activity of cisplatin. Naunyn. Schmiedebergs Arch. Pharmacol. 389, 485-497.

Jiang, Y., Li, M., Zhang, Z., Gong, T., Sun, X., 2014. Cell-penetrating peptides as delivery enhancers for vaccine. Curr. Pharm. Biotechnol. 15, 256-266.

Jo, D., Nashabi, A., Doxsee, C., Lin, Q., Unutmaz, D., Chen, J., Ruley, H.E., 2001. Epigenetic regulation of gene structure and function with a cell-permeable Cre recombinase. Nat. Biotechnol. 19, 929-933.

Jones, A.T., Sayers, E.J., 2012. Cell entry of cell penetrating peptides: tales of tails wagging dogs. J. Control. Release 161, 582-591.

Kaitsuka, T., Tomizawa, K., 2015. Cell-penetrating peptide as a means of directing the differentiation of induced-pluripotent stem cells. Int. J. Mol. Sci. 16, 26667-26676.

Kanasty, R., Dorkin, J.R., Vegas, A., Anderson, D., 2013. Delivery materials for siRNA therapeutics. Nat. Mater. 12, 967-977.

Karagiannis, E.D., Urbanska, A.M., Sahay, G., Pelet, J.M., Jhunjhunwala, S., Langer, R., Anderson, D.G., 2013. Rational design of a biomimetic cell penetrating peptide library. ACS Nano 7, 8616-8626.

Kato, T., Okada, S., Yutaka, T., Yabuuchi, H., 1984. The effects of sucrose loading on lysosomal hydrolases. Mol. Cell. Biochem. 60, 83-98.

Keefer, C.L., 2004. Production of bioproducts through the use of transgenic animal models. Anim. Reprod. Sci. 82 (83), 5-12.

Kerkis, A., Kerkis, I., Radis-Baptista, G., Oliveira, E.B., Vianna-Morgante, A.M., Pereira, L.V., Yamane, T., 2004. Crotamine is a novel cell-penetrating protein from the venom of rattlesnake Crotalus durissus terrificus. FASEB J. 18, 1407-1409.

Kerkis, I., Silva Fde, S., Pereira, A., Kerkis, A., Radis-Baptista, G., 2010. Biological versatility of crotamine-a cationic peptide from the venom of a South American rattlesnake. Expert Opin. Investig. Drugs 19, 1515-1525.

Kerkis, I., de Brandao Prieto da Silva, A.R., Pompeia, C., Tytgat, J., de Sa Junior, P.L., 2016. Toxin bioportides: exploring toxin biological activity and multifunctionality. Cell. Mol. Life Sci. 74, 647-661. http://dx.doi.org/10.1007/s00018-016-2343-6.

Kim, M.J., Park, M., Kim, D.W., et al., 2015. Transduced PEP-1-PON1 proteins regulate microglial activation and dopaminergic neuronal death in a Parkinson's disease model. Biomaterials $64,45-56$.

Kim, J.S., 2016. Genome editing comes of age. Nat. Protoc. 11, 1573-1578.

Kind, A., Schnieke, A., 2008. Animal pharming, two decades on. Transgenic Res. 17, 
$1025-1033$.

Kizil, C., Iltzsche, A., Thomas, A.K., Bhattarai, P., Zhang, Y., Brand, M., 2015. Efficient cargo delivery into adult brain tissue using short cell-penetrating peptides. PLoS One 10, e0124073.

Kleemann, E., Neu, M., Jekel, N., Fink, L., Schmehl, T., Gessler, T., Seeger, W., Kissel, T., 2005. Nano-carriers for DNA delivery to the lung based upon a TAT-derived peptide covalently coupled to PEG-PEI. J. Control. Release 109, 299-316.

Kole, R., Krainer, A.R., Altman, S., 2012. RNA therapeutics: beyond RNA interference and antisense oligonucleotides. Nat. Rev. Drug Discov. 11, 125-140.

Koren, E., Torchilin, V.P., 2012. Cell-penetrating peptides: breaking through to the other side. Trends Mol. Med. 18, 385-393.

Kues, W.A., Niemann, H., 2004. The contribution of farm animals to human health. Trends Biotechnol. 22, 286-294.

Laible, G., Alonso-Gonzalez, L., 2009. Gene targeting from laboratory to livestock: current status and emerging concepts. Biotechnol. J. 4, 1278-1292.

Lamiable, A., Thevenet, P., Rey, J., Vavrusa, M., Derreumaux, P., Tuffery, P., 2016. PEPFOLD3: faster de novo structure prediction for linear peptides in solution and in complex. Nucleic Acids Res. 44, W449-454.

Lehto, T., Kurrikoff, K., Langel, U., 2012. Cell-penetrating peptides for the delivery of nucleic acids. Expert Opin. Drug Deliv. 9, 823-836.

Li, Z.Y., Wong, F., Chang, J.H., Possin, D.E., Hao, Y., Petters, R.M., Milam, A.H., 1998. Rhodopsin transgenic pigs as a model for human retinitis pigmentosa. Investig. Ophthalmol. Vis. Sci. 39, 808-819.

Lim, S., Koo, J.H., Choi, J.M., 2016. Use of cell-penetrating peptides in dendritic cellbased vaccination. Immune Netw. 16, 33-43.

Lindgren, M., Hallbrink, M., Prochiantz, A., Langel, U., 2000. Cell-penetrating peptides. Trends Pharmacol. Sci. 21, 99-103.

Liu, Y., Yang, J.Y., Lu, Y., Yu, P., Dove, C.R., Hutcheson, J.M., Mumaw, J.L., Stice, S.L., West, F.D., 2013. alpha-1, 3-Galactosyltransferase knockout pig induced pluripotent stem cells: a cell source for the production of xenotransplant pigs. Cell. Reprogramm. 15, 107-116.

Liu, J., Gaj, T., Patterson, J.T., Sirk, S.J., Barbas 3rd, C.F., 2014. Cell-penetrating peptidemediated delivery of TALEN proteins via bioconjugation for genome engineering. PLoS One 9, e85755.

Madani, F., Lindberg, S., Langel, U., Futaki, S., Graslund, A., 2011. Mechanisms of cellular uptake of cell-penetrating peptides. J. Biophys. 2011, 414729 (Hindawi Publishing Corporation: Online).

Maggio, I., Holkers, M., Liu, J., Janssen, J.M., Chen, X., Goncalves, M.A., 2014. Adenoviral vector delivery of RNA-guided CRISPR/Cas9 nuclease complexes induces targeted mutagenesis in a diverse array of human cells. Sci. Rep. 4, 5105.

Mai, J.C., Shen, H., Watkins, S.C., Cheng, T., Robbins, P.D., 2002. Efficiency of protein transduction is cell type-dependent and is enhanced by dextran sulfate. J. Biol. Chem. 277, 30208-30218.

Maiolo, J.R., Ferrer, M., Ottinger, E.A., 2005. Effects of cargo molecules on the cellular uptake of arginine-rich cell-penetrating peptides. Biochim. Biophys. Acta 16, 161-172.

Mann, D.A., Frankel, A.D., 1991. Endocytosis and targeting of exogenous HIV-1 Tat protein. EMBO J. 10, 1733-1739.

Matsubara, Y., Chiba, T., Kashimada, K., Morio, T., Takada, S., Mizutani, S., Asahara, H., 2014. Transcription activator-like effector nuclease-mediated transduction of exogenous gene into IL2RG locus. Sci. Rep. 4, 5043.

Matsumoto, R., Okochi, M., Shimizu, K., Kanie, K., Kato, R., Honda, H., 2015. Effects of the properties of short peptides conjugated with cell-penetrating peptides on their internalization into cells. Sci. Rep. 5, 12884.

Maurisse, R., De Semir, D., Emamekhoo, H., Bedayat, B., Abdolmohammadi, A., Parsi, H., Gruenert, D.C., 2010. Comparative transfection of DNA into primary and transformed mammalian cells from different lineages. BMC Biotechnol. 10, 9.

McClorey, G., Wood, M.J., 2015. An overview of the clinical application of antisense oligonucleotides for RNA-targeting therapies. Curr. Opin. Pharmacol. 24, 52-58.

Mehier-Humbert, S., Guy, R.H., 2005. Physical methods for gene transfer: improving the kinetics of gene delivery into cells. Adv. Drug Deliv. Rev. 57, 733-753.

Mellman, I., Fuchs, R., Helenius, A., 1986. Acidification of the endocytic and exocytic pathways. Annu. Rev. Biochem. 55, 663-700.

Morris, M.C., Depollier, J., Mery, J., Heitz, F., Divita, G., 2001. A peptide carrier for the delivery of biologically active proteins into mammalian cells. Nat. Biotechnol. 19, 1173-1176.

Nakase, I., Kobayashi, S., Futaki, S., 2010. Endosome-disruptive peptides for improving cytosolic delivery of bioactive macromolecules. Biopolymers 94, 763-770.

Nascimento, F.D., Hayashi, M.A., Kerkis, A., Oliveira, V., Oliveira, E.B., Radis-Baptista, G., Nader, H.B., Yamane, T., Tersariol, I.L., Kerkis, I., 2007. Crotamine mediates gene delivery into cells through the binding to heparan sulfate proteoglycans. J. Biol. Chem. 282, 21349-21360.

Nielsen, E.J., Yoshida, S., Kamei, N., Iwamae, R., Khafagy el, S., Olsen, J., Rahbek, U.L., Pedersen, B.L., Takayama, K., Takeda-Morishita, M., 2014. In vivo proof of concept of oral insulin delivery based on a co-administration strategy with the cell-penetrating peptide penetratin. J. Control. Release 189, 19-24.

Oehlke, J., Scheller, A., Wiesner, B., Krause, E., Beyermann, M., Klauschenz, E., Melzig, M., Bienert, M., 1998. Cellular uptake of an alpha-helical amphipathic model peptide with the potential to deliver polar compounds into the cell interior non-endocytically. Biochim. Biophys. Acta 1414, 127-139.

Park, H., Tsutsumi, H., Mihara, H., 2013. Cell penetration and cell-selective drug delivery using alpha-helix peptides conjugated with gold nanoparticles. Biomaterials 34 , 4872-4879.

Persson, D., Thoren, P.E., Norden, B., 2001. Penetratin-induced aggregation and subsequent dissociation of negatively charged phospholipid vesicles. FEBS Lett. 505, 307-312.
Pettersen, E.F., Goddard, T.D., Huang, C.C., Couch, G.S., Greenblatt, D.M., Meng, E.C., Ferrin, T.E., 2004. UCSF Chimera-a visualization system for exploratory research and analysis. J. Comput. Chem. 25, 1605-1612.

Pooga, M., Langel, U., 2015. Classes of cell-penetrating peptides. Methods Mol. Biol. (Clifton, NJ) 1324, 3-28.

Pooga, M., Hallbrink, M., Zorko, M., Langel, U., 1998. Cell penetration by transportan. FASEB J. 12, 67-77.

Poon, G.M., Gariepy, J., 2007. Cell-surface proteoglycans as molecular portals for cationic peptide and polymer entry into cells. Biochem. Soc. Trans. 35, 788-793.

Pruett-Miller, S.M., Reading, D.W., Porter, S.N., Porteus, M.H., 2009. Attenuation of zinc finger nuclease toxicity by small-molecule regulation of protein levels. PLoS Genet. 5, e1000376.

Qian, Z., Dougherty, P.G., Pei, D., 2015. Monitoring the cytosolic entry of cell-penetrating peptides using a pH-sensitive fluorophore. Chem. Commun. (Camb.) 51, 2162-2165.

Raagel, H., Saalik, P., Hansen, M., Langel, U., Pooga, M., 2009. CPP-protein constructs induce a population of non-acidic vesicles during trafficking through endo-lysosomal pathway. J. Control. Release 139, 108-117.

Radis-Baptista, G., Kerkis, I., 2011. Crotamine, a small basic polypeptide myotoxin from rattlesnake venom with cell-penetrating properties. Curr. Pharm. Des. 17, 4351-4361.

Radis-Baptista, G., de la Torre, B.G., Andreu, D., 2008. A novel cell-penetrating peptide sequence derived by structural minimization of a snake toxin exhibits preferential nucleolar localization. J. Med. Chem. 51, 7041-7044.

Ramakrishna, S., Kwaku Dad, A.B., Beloor, J., Gopalappa, R., Lee, S.K., Kim, H., 2014. Gene disruption by cell-penetrating peptide-mediated delivery of Cas9 protein and guide RNA. Genome Res. 24, 1020-1027.

Regberg, J., Srimanee, A., Langel, U., 2012. Applications of cell-penetrating peptides for tumor targeting and future cancer therapies. Pharmaceuticals (Basel, Switzerland) 5, $991-1007$.

Regberg, J., Eriksson, J.N., Langel, U., 2013. Cell-penetrating peptides: from cell cultures to in vivo applications. Front. Biosci. (Elite edition) 5, 509-516.

Rennert, R., Wespe, C., Beck-Sickinger, A.G., Neundorf, I., 2006. Developing novel hCT derived cell-penetrating peptides with improved metabolic stability. Biochim. Biophys. Acta 34, 347-354.

Richt, J.A., Kasinathan, P., Hamir, A.N., et al., 2007. Production of cattle lacking prion protein. Nat. Biotechnol. 25, 132-138.

Rizzuti, M., Nizzardo, M., Zanetta, C., Ramirez, A., Corti, S., 2015. Therapeutic applications of the cell-penetrating HIV-1 Tat peptide. Drug Discov. Today 20, 76-85.

Rodrigues, M., de la Torre, B.G., Radis-Baptista, G., Santos, N.C., Andreu, D., 2011. Efficient cellular delivery of beta-galactosidase mediated by NrTPs, a new family of cell-penetrating peptides. Bioconjug. Chem. 22, 2339-2344.

Roeder, G.E., Parish, J.L., Stern, P.L., Gaston, K., 2004. Herpes simplex virus VP22-human papillomavirus E2 fusion proteins produced in mammalian or bacterial cells enter mammalian cells and induce apoptotic cell death. Biotechnol. Appl. Biochem. 40, $157-165$.

Ru, R., Yao, Y., Yu, S., Yin, B., Xu, W., Zhao, S., Qin, L., Chen, X., 2013. Targeted genome engineering in human induced pluripotent stem cells by penetrating TALENs. Cell Regen. (London, England) 2, 5.

Sandgren, S., Cheng, F., Belting, M., 2002. Nuclear targeting of macromolecular polyanions by an HIV-Tat derived peptide. Role for cell-surface proteoglycans. J. Biol. Chem. 277, 38877-38883.

Shukla, R.S., Qin, B., Cheng, K., 2014. Peptides used in the delivery of small noncoding RNA. Mol. Pharm. 11, 3395-3408.

Soler, M., Gonzalez-Bartulos, M., Soriano-Castell, D., Ribas, X., Costas, M., Tebar, F., Massaguer, A., Feliu, L., Planas, M., 2014. Identification of BP16 as a non-toxic cellpenetrating peptide with highly efficient drug delivery properties. Org. Biomol. Chem. 12, 1652-1663.

Sonsteng, K.M., Prigge, J.R., Talago, E.A., June, R.K., Schmidt, E.E., 2014. Hydrodynamic delivery of Cre protein to lineage-mark or time-stamp mouse hepatocytes in situ. PLoS One 9, e91219.

Sovova, T., Kerins, G., Demnerova, K., Ovesna, J., 2016. Genome editing with engineered nucleases in economically important animals and plants: state of the art in the research pipeline. Curr. Issues Mol. Biol. 21, 41-62.

Stewart, K.M., Horton, K.L., Kelley, S.O., 2008. Cell-penetrating peptides as delivery vehicles for biology and medicine. Orga. Biomol. Chem. 6, 2242-2255.

Stone, J., 1998. An Efficient Library for Parallel Ray Tracing and Animation. PhD Dissertation. University of Missouri, Rolla, MO.

Sun, Y., Hu, Y.H., 2015. Cell-penetrating peptide-mediated subunit vaccine generates a potent immune response and protection against Streptococcus iniae in Japanese flounder (Paralichthys olivaceus). Vet. Immunol. Immunopathol. 167, 96-103.

Thompson, S., Clarke, A.R., Pow, A.M., Hooper, M.L., Melton, D.W., 1989. Germ line transmission and expression of a corrected HPRT gene produced by gene targeting in embryonic stem cells. Cell 56, 313-321.

Tiriveedhi, V., Butko, P., 2007. A fluorescence spectroscopy study on the interactions of the TAT-PTD peptide with model lipid membranes. Biochemistry 46, 3888-3895.

Tisseyre, C., Bahembera, E., Dardevet, L., Sabatier, J.M., Ronjat, M., De Waard, M., 2013. Cell penetration properties of a highly efficient mini maurocalcine peptide. Pharmaceuticals (Basel, Switzerland) 6, 320-339.

Torchilin, V.P., 2006. Recent approaches to intracellular delivery of drugs and DNA and organelle targeting. Annu. Rev. Biomed. Eng. 8, 343-375.

Torchilin, V.P., 2008. Cell penetrating peptide-modified pharmaceutical nanocarriers for intracellular drug and gene delivery. Biopolymers 90, 604-610.

Violini, S., Sharma, V., Prior, J.L., Dyszlewski, M., Piwnica-Worms, D., 2002. Evidence for a plasma membrane-mediated permeability barrier to Tat basic domain in welldifferentiated epithelial cells: lack of correlation with heparan sulfate. Biochemistry 41, 12652-12661. 
Vives, E., Brodin, P., Lebleu, B., 1997. A truncated HIV-1 Tat protein basic domain rapidly translocates through the plasma membrane and accumulates in the cell nucleus. J. Biol. Chem. 272, 16010-16011.

Wadia, J.S., Stan, R.V., Dowdy, S.F., 2004. Transducible TAT-HA fusogenic peptide enhances escape of TAT-fusion proteins after lipid raft macropinocytosis. Nat. Med. 10, 310-315.

Walrant, A., Correia, I., Jiao, C.Y., Lequin, O., Bent, E.H., Goasdoue, N., Lacombe, C., Chassaing, G., Sagan, S., Alves, I.D., 2011. Different membrane behaviour and cellular uptake of three basic arginine-rich peptides. Biochim. Biophys. Acta 38, 382-393.

Walther, C., Ott, I., Gust, R., Neundorf, I., 2009. Specific labeling with potent radiolabels alters the uptake of cell-penetrating peptides. Biopolymers 92, 445-451.

Wang, H.Y., Wang, R.F., 2012. Enhancing cancer immunotherapy by intracellular delivery of cell-penetrating peptides and stimulation of pattern-recognition receptor signaling. Adv. Immunol. 114, 151-176.

Wanjale, M.V., Kumar, G.S., 2016. Peptides as a therapeutic avenue for nanocarrier-aided targeting of glioma. Expert Opin. Drug Deliv.
Wharton, S.A., Martin, S.R., Ruigrok, R.W., Skehel, J.J., Wiley, D.C., 1988. Membrane fusion by peptide analogues of influenza virus haemagglutinin. J. Gen. Virol. 69 (Pt. 8), 1847-1857.

Wright, G., Carver, A., Cottom, D., Reeves, D., Scott, A., Simons, P., Wilmut, I., Garner, I., Colman, A., 1991. High level expression of active human alpha-1-antitrypsin in the milk of transgenic sheep. Biotechnology 9, 830-834 (Nature Publishing Company).

Xu, Y., Liu, S., Yu, G., Chen, J., Chen, J., Xu, X., Wu, Y., Zhang, A., Dowdy, S.F., Cheng, G., 2008. Excision of selectable genes from transgenic goat cells by a protein transducible TAT-Cre recombinase. Gene 419, 70-74.

Yu, X., Wang, Y., Xia, Y., Zhang, L., Yang, Q., Lei, J., 2016. A DNA vaccine encoding VP22 of herpes simplex virus type I (HSV-1) and OprF confers enhanced protection from Pseudomonas aeruginosa in mice. Vaccine 34, 4399-4405.

Zhou, Y., Zhang, W., Mai, K., et al., 2012. TAT improves in vitro transportation of fortilin through midgut and into hemocytes of white shrimp Litopenaeus vannamei. J. Ocean Univ. China 11, 197-204.

Ziegler, A., 2008. Thermodynamic studies and binding mechanisms of cell-penetrating peptides with lipids and glycosaminoglycans. Adv. Drug Deliv. Rev. 60, 580-597. 